\title{
THE MUSEUM OF ALL MUSEUMS
}

\section{FEDERICO SORIANO}

Profesor, Escuela Técnica Superior

de Arquitectura de Madrid, ETSAM

Madrid, España

\section{9}

Proyecto / Project

Keywords

Collection

Postproduction

Recycling

Concept

Image

\section{DOLORES PALACIOS}

Soriano y Asociados arquitectos

Madrid, España

In a context where everything has already been created and where we have already seen all images, this project applies a different logic: replace production with postproduction - that is, manipulating already popular images to generate something new from them. Thus, through a collection of 100 existing museums, a fresh image, concept and project are developed for the new Taipei City Museum of Art.

\section{Ideas on architecture}

Do you want just another design? Just another form? One that resembles many others? Just another one among the endless collection of forms generated in recent years? Do you want an object? An object to be built and shortly forgotten? One to be stored on the shelves belonging to that which is old-fashioned?

Or do we want to change and think about ideas rather than objects? Think about concepts and processes; raise matters; pursue paths; let ideas prevail over formal aspects; leave the final solution as a mere support; work outside time and fashions. This seems to be appropriate when designing a museum of conceptual art. The concept is the work itself.

Architecture is the visualization of a building process: it generates forms. In the end, these will be objects but their purpose is different: to meet certain goals (to respond to a certain program, to be an image of our time's culture, to engage in a dialogue with society, to encourage the public realm, to comply with environmental commitments...). What is important is to conceive a process that optimizes these ingredients once confronted with an idea. The concept is a process. 


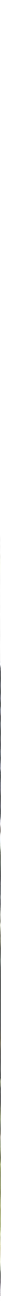

As architects, we see ideas. We explore concepts. We abstract nature. We support masses with light. We vaporize stone. We solidify perceptions. We architects can change the essence of a thing for a substance opposite to the original and make it work. The concept manipulates materials as it builds realities.

We have produced a lot, maybe too much. All the images in the world have already been printed. All forms in the world have already been visualized. All possible objects already exist. We can see them; they populate the Internet, virtual libraries, television, and our culture. If we are respectful to history, then let us retrieve all those images and value them today. We do not have to create any more. We only have to manipulate. The objects are already here. The concept is their manipulation.

In the contemporary world of recycling, production becomes postproduction. Originality and invention go from the object to its manipulation. The same happens within architecture. Through a contemporary lens, everything can be seen as current architecture. Old buildings, but also that which does not belong to our discipline. Postproduction is the concept.
1 Imagen de proyecto / Project image 
It is not fireworks, but neither an empty space. It is not a place without memory. It is a stroll. The public moves freely without necessarily following the planned routes. It is both educational and recreational. It is a public space where anything can happen. It is multiple collections all at once.

A museum for conceptual art, how is it? It is a museum that comprises all of the museums around the world - the real, the imagined and the possible ones. It is a museum that is a conceptual work of art on museums themselves, or on architecture. It is a museum recreated by the user. The visitor handles what he sees, what he thinks he sees, what he imagines he sees, and what he has been explained will see.

\section{Design idea}

A museum containing all museums. A museum that is the sum of the world's finest institutions. We collected 100 art museums worldwide. The most important ones. Understanding architecture as sheer abstraction of a historical landscape. A collection of generic plan fragments from museums around the world will be injected at the Taipei City Museum of Art.

The fragments synthesized from this collection of 100 art museums around the world are associated by geometry and surface to a specific use. Programs are the refined and systematic agglutination of forms with coordinated uses.

The sets are buried underground. Spaces are quite varied. Tours are flexible. The connections allow to reorganize space and circulations. The pieces are vertically connected generating controlled lighting courtyards. There are different rooms with artificial light to preserve works of art.

The museum of all museums arises as fragments in a garden of bamboo swaying in the air. Reeds, in their pendular movement, show glimpses of the building. Out of the original one hundred, only a few have truly emerged. But once inside we are in the museum of all museums.

\section{The city}

In order to build a connection with the city and the public systems it is not necessary to generate gateways, tunnels or vertices to pull us away from the surroundings. It is enough to have a focal point, an attractor among the landscape so as to get to it. A direction is enough. An urban landmark. Reaching to the museum is a pleasant walk, an urban experience.

A utility road - hidden among the vegetation - solves vehicular access to facility areas and mechanized parking lots from the avenue that surrounds the park.

\section{The museum}

The museum consists of two underground levels for exhibition spaces and a set of projecting volumes: lobbies, entrances and commercial spaces. Parking lots and all the systems necessary for the museum's energetic efficiency are at the foundations. 


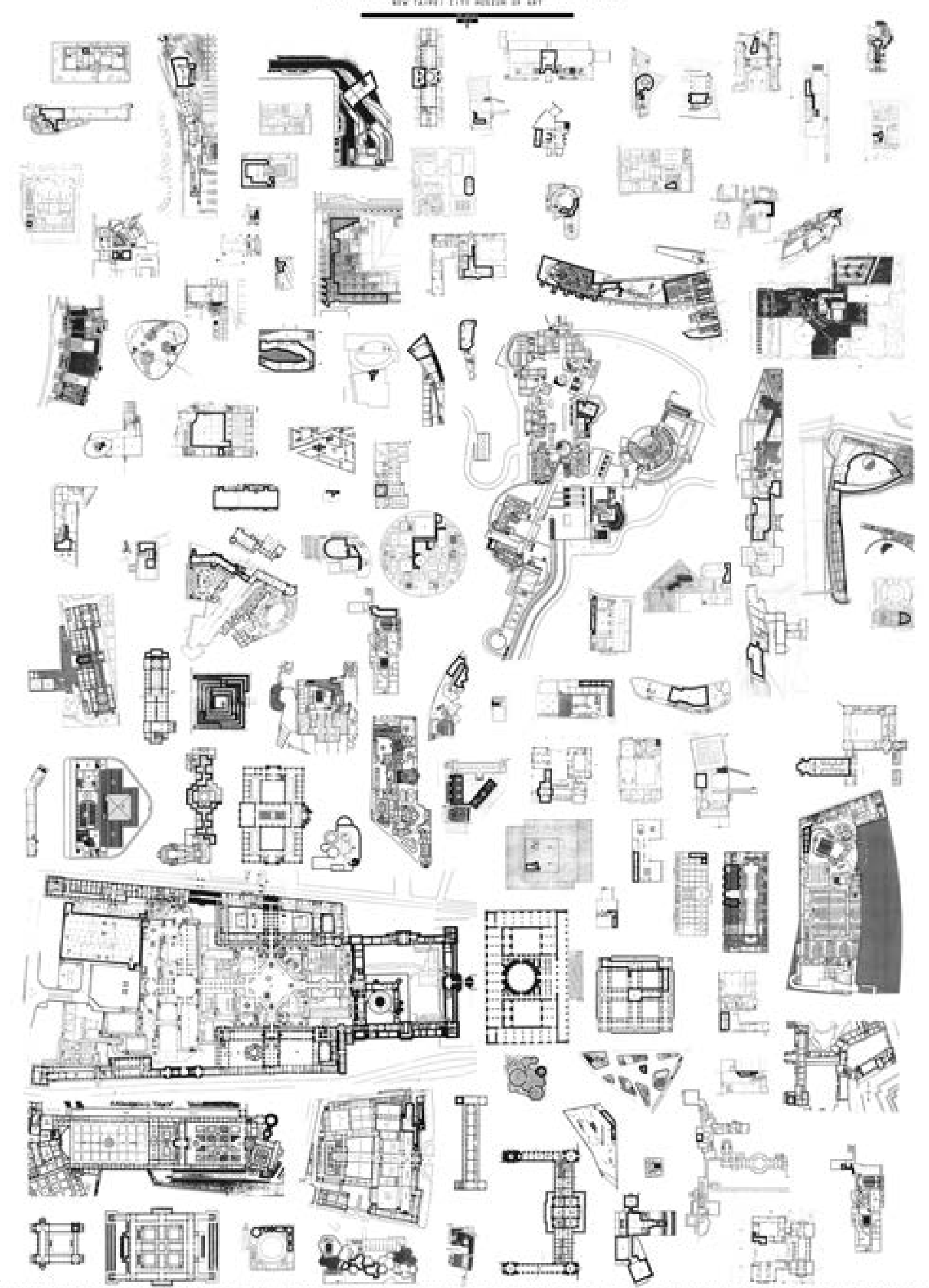


THE MUSE UH OF ALL MUSEUMS

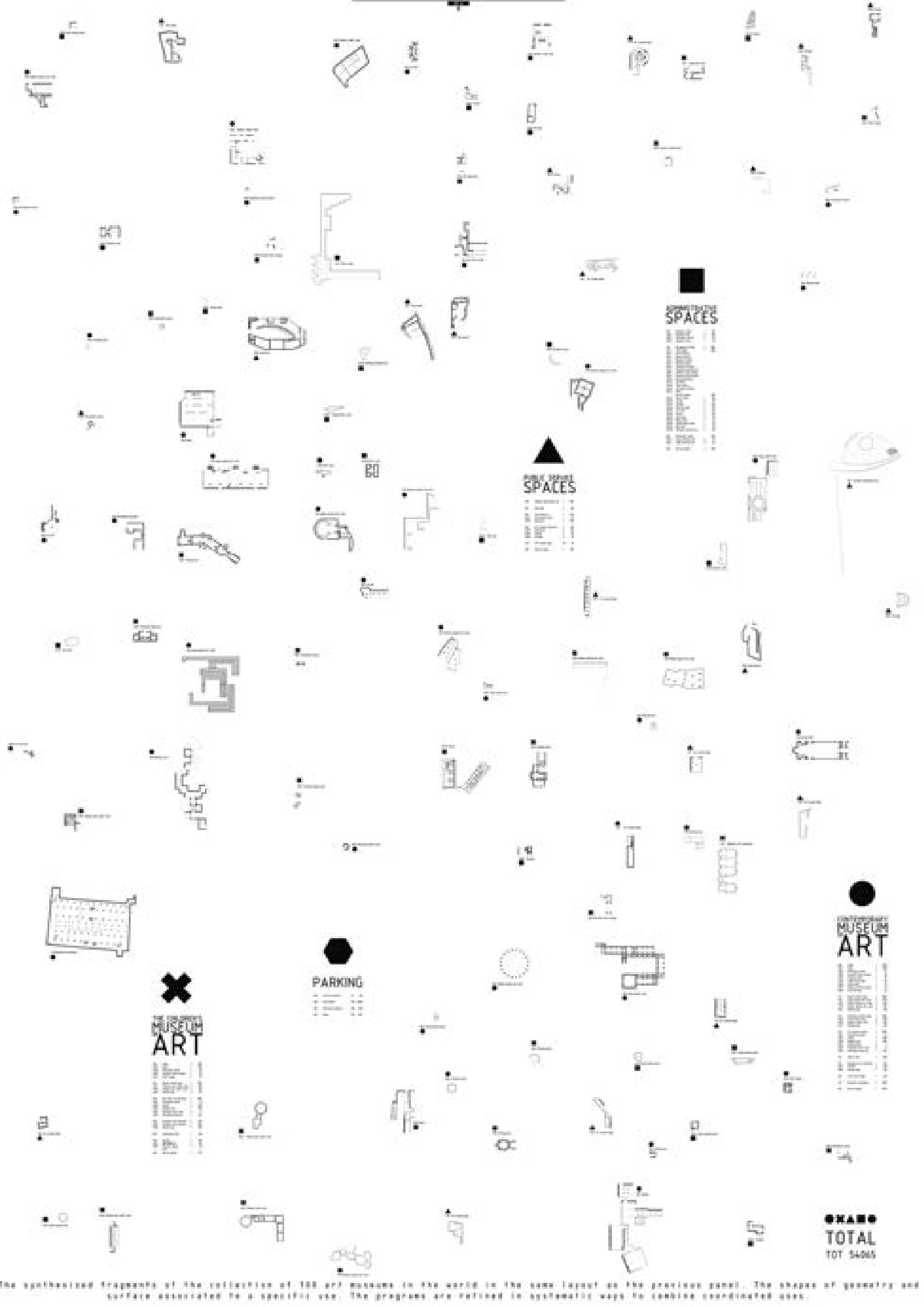




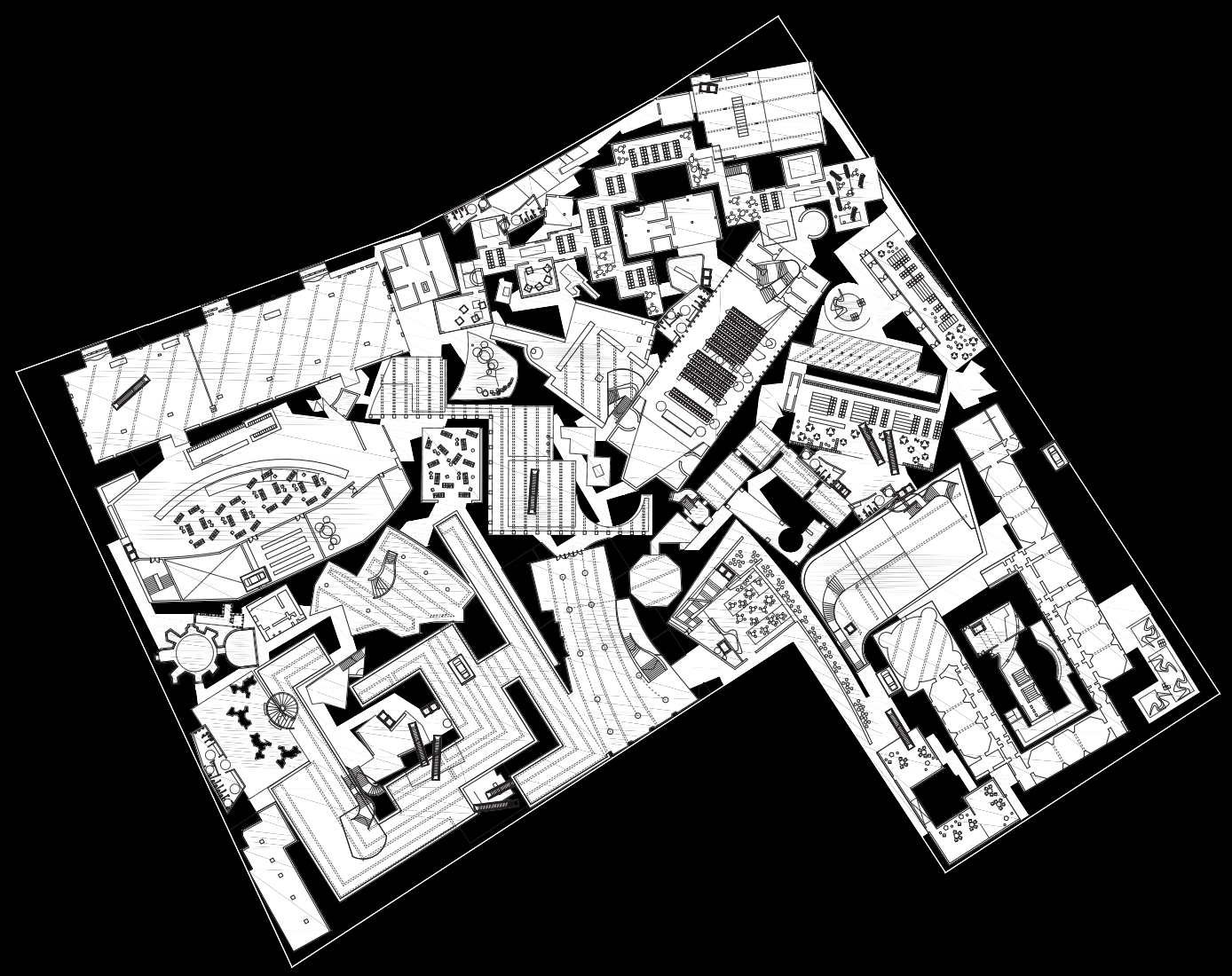

Planta nivel -2 /

Plan level -2
S.E. / N. S.

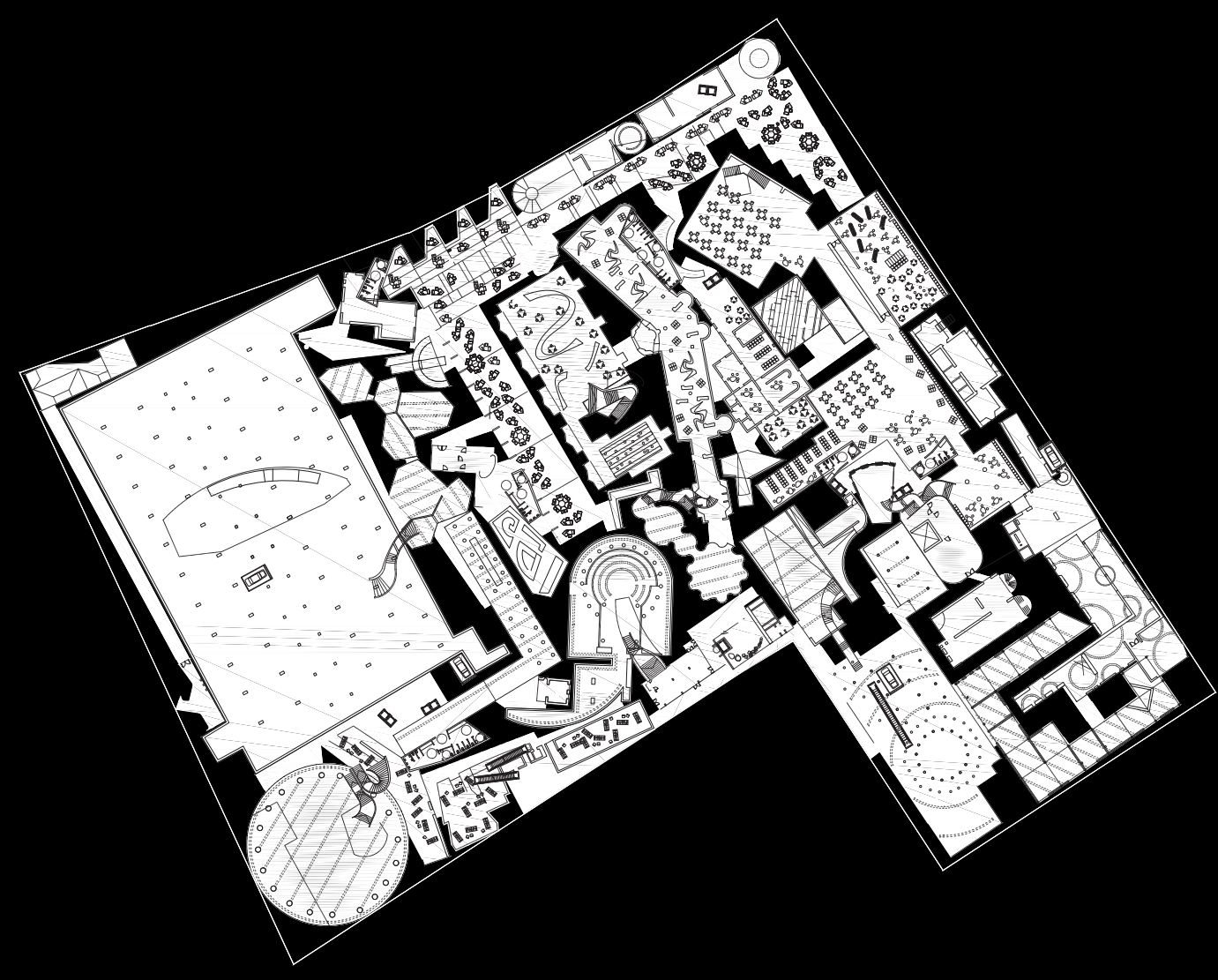




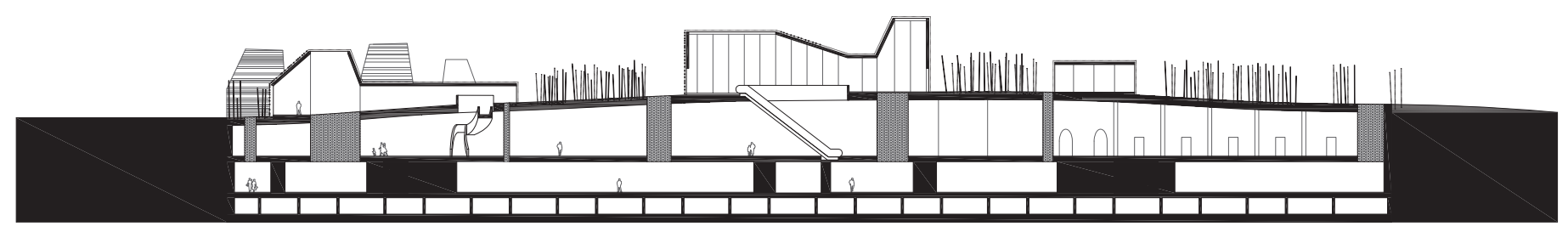

Corte CC / Section CC

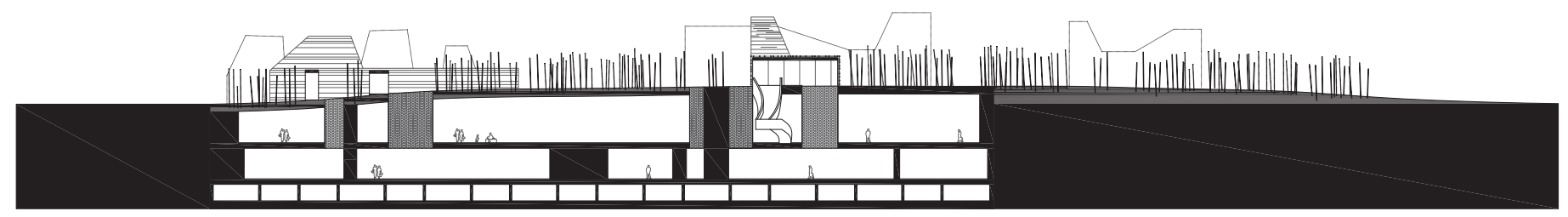

Corte DD / Section DD

S.E. / N.S

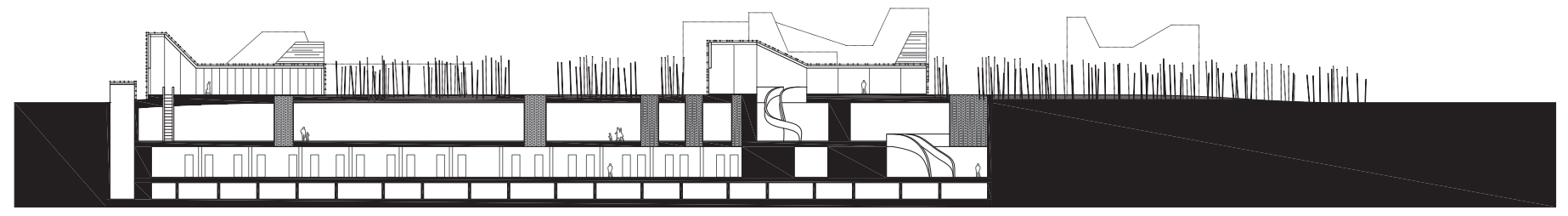




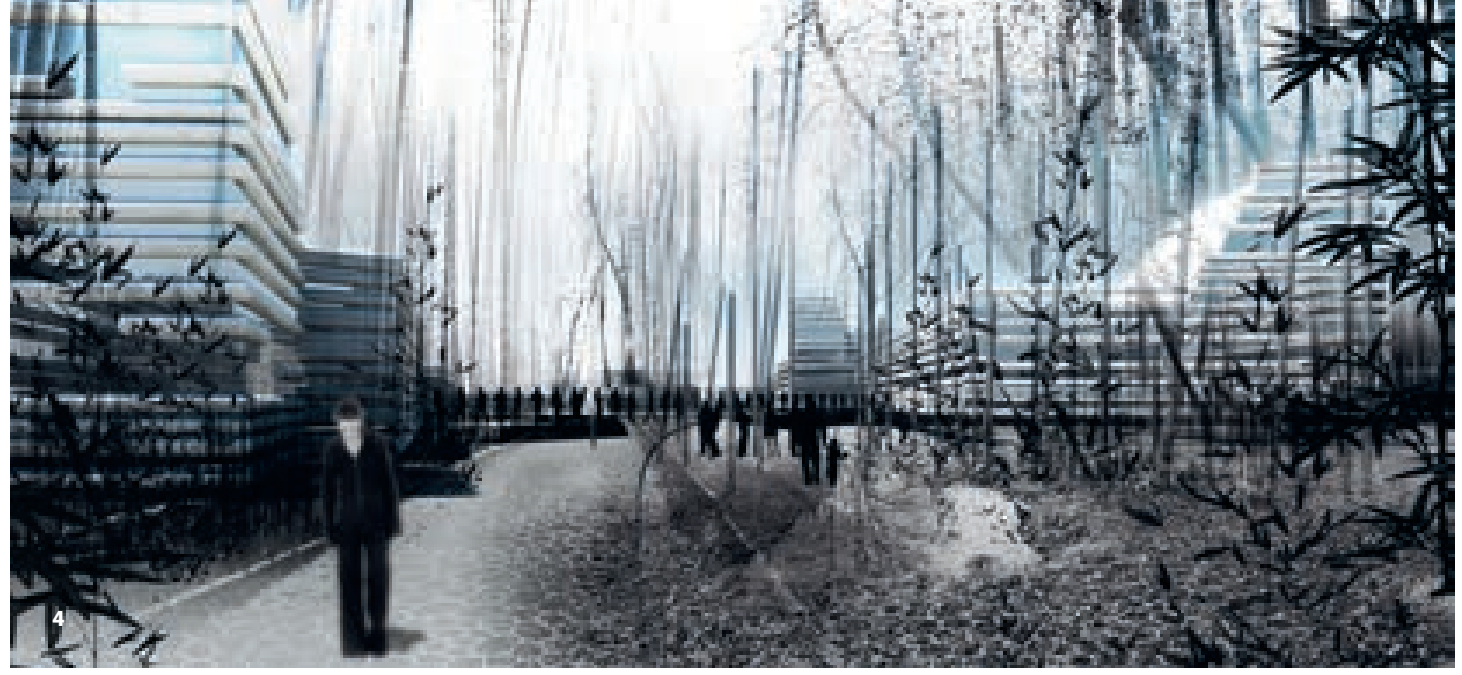

4 Imagen de proyecto /

Project image

5 Esquemas de sistemas

de circulación /

Circulation scheme
The rooms combine generating multiple physical connections between them. Superimposed routes dictated by curators and educators define the order. However, order is not important.

We have differentiated the pieces whose genetic origin is a museum from those added spaces in order to give continuity to the complex. The former will be built on abstract materials (white floors and walls) while the latter will have an earthly character (stone materials).

On this pattern of forms - an architectural patchwork - a system of corridors, stairs and elevators has been overlaid, which allows solving all circulations: possible (cultural routes), necessary (for service personnel), and mandatory (fire exits, art pieces management)

Superimposed to the previous layout, several possible routes have been established: permanent collection, temporary exhibitions, children's museum, conference room, commercial spaces, leisure areas, restoration space, administration and mechanical services. Each one has its own route, with its independent entrance and exit points.

The museum's collections can be toured independently following each route or in a linear, successive way. All entrances and exits come together in the main lobby. Also, each collection can be visited following exclusively masterpieces, narrative or educational tours.

The building's cross-section arises from the consideration of a safety margin as regards water table levels. Nothing is built underwater. In order to give the plans continuity, double and triple height voids have been introduced. Their dimensions extend circulations, views and spaces. Many of these voids are prolonged into the volumes that emerge in the garden. The sections show the two exhibition levels resting on the massive foundation of the building's mechanical systems and parking lot. This action releases the rooftop and the emerging volumes, turning them into landscape pieces on the garden. ARQ 


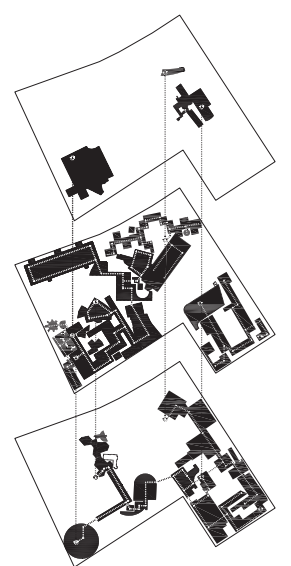

- All

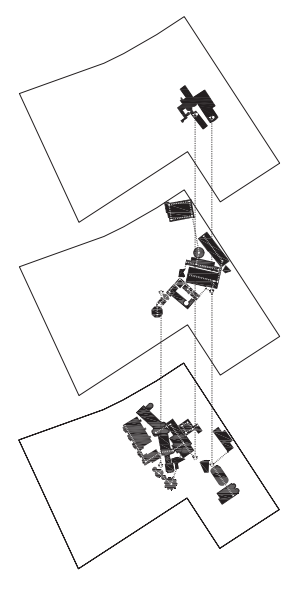

* Childrens museum

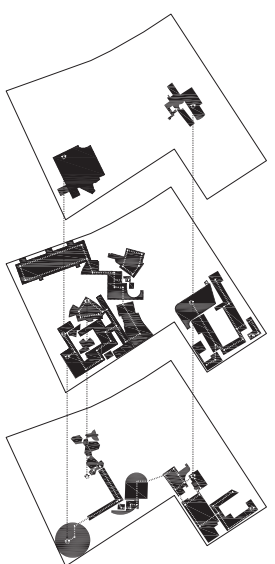

- All exhibition spaces

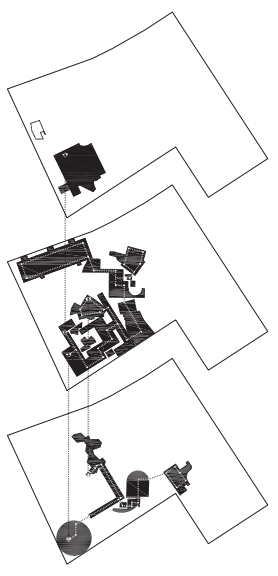

- Special exhibition spaces

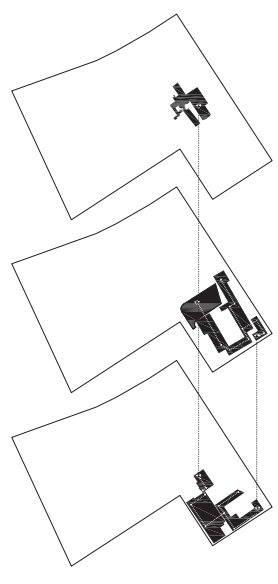

- Permanent exhibition spaces

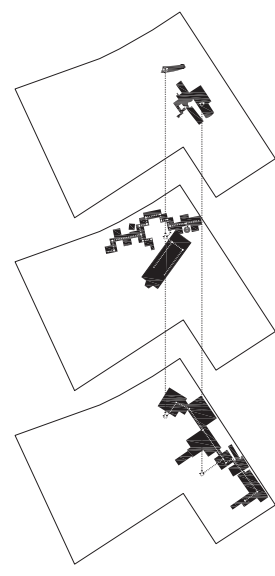

- Auditorium, library and classrooms
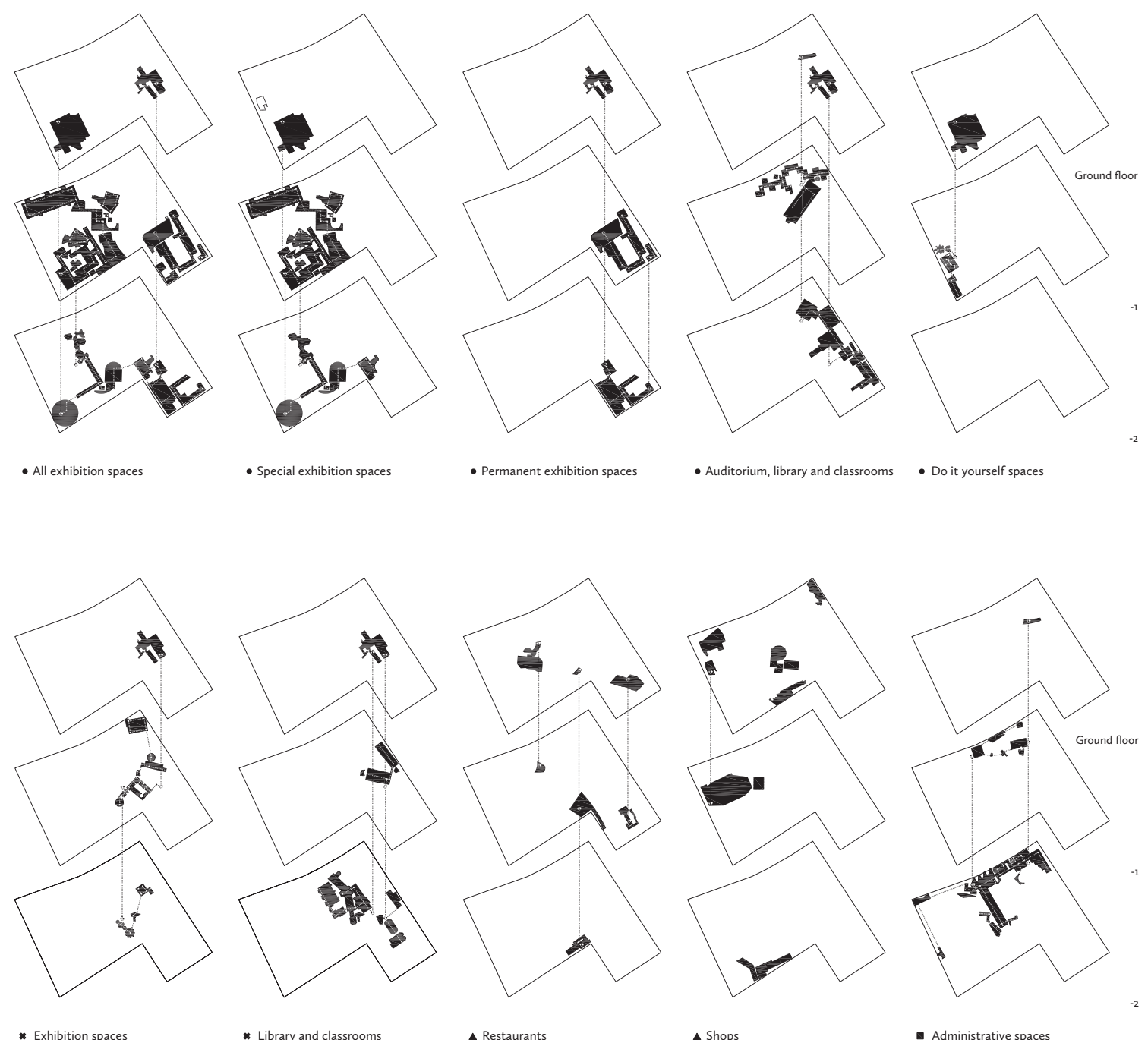

* Library and classrooms

\ Restaurants

$\Delta$ Shops

- Administrative spaces

EL MUSEO DE TODOS LOS MUSEOS

THE MUSEUM OF ALL MUSEUMS

Arquitectos / Architects: S\&Aa, Federico Soriano y Dolores Palacios.

Colaboradores / Collaborators: Carolina Cabello, Ana Pereira,

Pedro Pitarch, Leticia Sáez Muñoyerro, Marcos Zaragoza.

Ubicación / Location: Huan-he Rd, Taipei, Taiwan.

Cliente / Client: New Taipei City Government (Concurso / Competition)

Superficie del proyecto / Project area: $51.045 \mathrm{~m}^{2}$

Superficie de terreno / Site area: $20.000 \mathrm{~m}^{2}$

Año de proyecto / Project year: 2011

\section{Federico Soriano}

federico@federicosoriano.com

Architect, Escuela Técnica Superior de Arquitectura de Madrid ETSA M, 1986. Doctor Architect, ETSAM, 2002. Along with Dolores Palacios he founded in 1992 the office Soriano y Asociados arquitectos. Since then, he alternates professional practice with teaching and research activities. Has been director of the magazines Arquitectura, from the Colegio Oficial de Arquitectos de Madrid, and Fisuras de la Cultura Contemporánea. Among his published books are Sin_tesis (Gustavo Gili, 2004), Metápolis. Diccionario de arquitectura avanzada (Actar, 2001) and Es pequeño, llueve dentro y hay hormigas (Actar, 2000). Visiting professor at Ferrara, Sassari and Calgary universities, he is currently Studio Professor at ETSAM. 